\title{
LEADERSHIP DILEMMAS IN A CHANGING BUSINESS ENVIRONMENT
}

\author{
Omar Saleh, Al Zaytoonah University of Jordan, Jordan \\ Jasser Al-Nasour, Al Zaytoonah University of Jordan, Jordan \\ Ghandi Eid Aldrou, Ministry of Higher Education and Scientific Research, Jordan
}

dx.doi.org/10.18374/IJBR-21-1.4

\begin{abstract}
As the social and environmental problems of business increase and the effects of competition increase in the physical and digital markets, leadership plays the most important role in facing these problems and challenges. Yet leadership in these companies faces complex and difficult dilemmas in today's business environment. From a review of the literature, previous studies have identified leadership dilemmas as threats and problems facing companies. This study sought to define leadership dilemmas as choices and initiatives undertaken by leadership that respond to the challenges of the competitive environment. In this study, five new leadership dilemmas were identified: the dilemma of a dynamic strategic vision, leadership continuity dilemma, lost opportunities, the digital dilemma and ethical dilemma
\end{abstract}

Keywords: Leadership, new leadership dilemmas, digital dilemma, ethical dilemma. 